\title{
Operative survival and 40 year follow up of surgical repair of aortic coarctation
}

\author{
J J Bobby, J M Emami, R D T Farmer, C G H Newman
}

\begin{abstract}
Objective-To study early and late mortality after surgical correction of coarctation of the aorta.
\end{abstract}

Design-Data on 223 patients operated on at the Westminster Hospital, London, between 1946 and 1981, were collected and updated by questionnaire.

Participants-All 223 patients recorded as undergoing operation for aortic coarctation up to the end of 1981 . Fifteen of 197 survivors were lost to follow up; most of them were patients from overseas.

Outcome and results-The early mortality (within one month of operation) was $12 \%$ overall, $2 \cdot 6 \%$ for elective surgery, and $0 \%$ for the 77 patients undergoing surgery since 1968 . Survivors were followed up for a total of 3288 patient years; in 27 follow up lasted more than 30 years. In a few it reached 40 years. Twenty two patients died during this period, 18 from causes that could be attributed to coarctation or its repair. Mortality was highest more than 20 years after the operation.

Conclusion-Repair increased life expectancy in patients with aortic coarctation. Late problems caused by persistent hypertension or recoarctation became apparent in long term survivors. The increased risk of late mortality associated with the duration of preoperative hypertension was not statistically significant. There were no deaths from cerebrovascular accidents. (In an earlier necropsy series cerebrovascular accidents accounted for $11.8 \%$ of deaths.) The incidence of deaths from aneurysms resembled that in the earlier necropsy series.

Operations to correct coarctation of the aorta

Department of

Community Medicine, Charing Cross and

Westminster Medical School, London

J J Bobby

J M Emami

R D T Farme

C G H Newman

Correspondence to

Dr C G H Newman

Department of Paediatric

Cardiology, Westminster

Hospital, Horseferry Road,

London SW1P 2AP.

Accepted for publication

4 January 1991 earliest correction in the United Kingdom was performed by Sir Clement Price Thomas at Westminster Hospital in London in 1946. We have assessed the survival of patients who had the operation at Westminster Hospital since 1946.

Patients and methods

Between 1946 and 1981223 patients with coarctation of the aorta were operated on at Westminster Hospital. Details of these have been carried out since $1944 .^{1{ }^{2}}$ The patients were extracted from their discharge summaries and operation notes and from necropsy reports where available. Those who survived the operation were followed up to assess their present condition. Some of these patients had been followed up for up to 40 years and so the series gives valuable information about long term mortality and morbidity in patients who have had surgical correction of congenital coarctation of the aorta.

Of the original 223 patients, $156(70 \%)$ were male. Thirty one $(14 \%)$ were less than one year old at operation, a further $39(17 \%)$ were 1 to 5 , and $85(38 \%)$ were aged from 5 to 15 . Of the remaining $68,15(7 \%)$ were over the age of 30; the oldest was 48 . Hypertension was common; about half the patients had a preoperative systolic blood pressure of $\geqslant 160 \mathrm{~mm} \mathrm{Hg}$. Forty patients had had a period of heart failure. Some patients had associated lesions-notably, 10 had a ventricular septal defect and 31 a ductus arteriosus of whom seven also had a ventricular septal defect. In most patients the coarctation was postductal, but in 14 patients the coarctation was described as preductal and in 23 as juxtaductal.

The most common surgical technique was resection of the coarctation with end-to-end anastomosis. No record of the use of a Dacron patch was found. The subclavian flap technique was increasingly used from 1974. Pulmonary artery banding was also carried out on eight patients presenting with complex lesions in infancy, and where there was a ductus this was ligated. Only two patients who had pulmonary banding as part of their treatment survived-one with established pulmonary vascular disease despite the band, and the other, who was treated for ventricular septal defect with double aortic arch and coarctation, was well when last seen (debanded with the ventricular septal defect closed) but with some evidence of recoarctation six years after operation. No neurological complications were seen.

The total follow up time was 3288 patient years. The length of follow up ranged from one month to 40 years, with 107 patients being followed up for over 15 years and 27 for more than 30 years.

Results

OPERATIVE SURVIVAL

For the purposes of this analysis the patients were divided into those who had an elective 


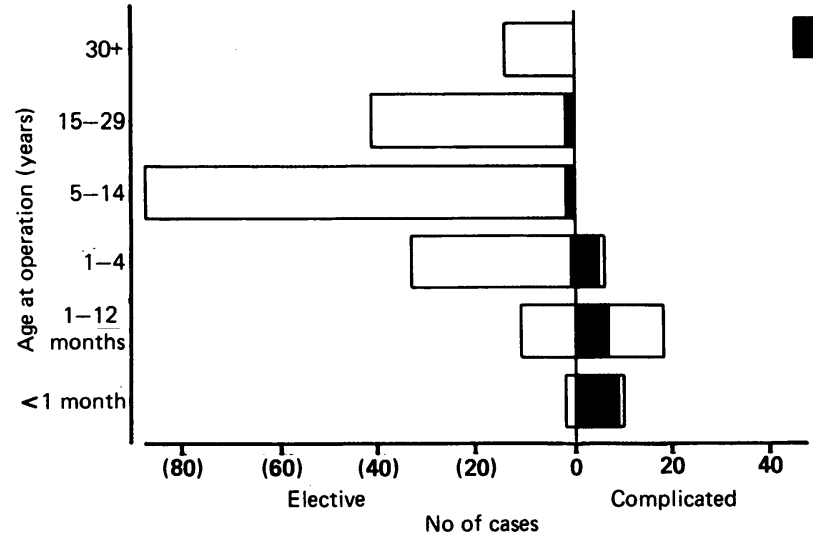

Figure 1 Deaths within 30 days of operation by age at operation.

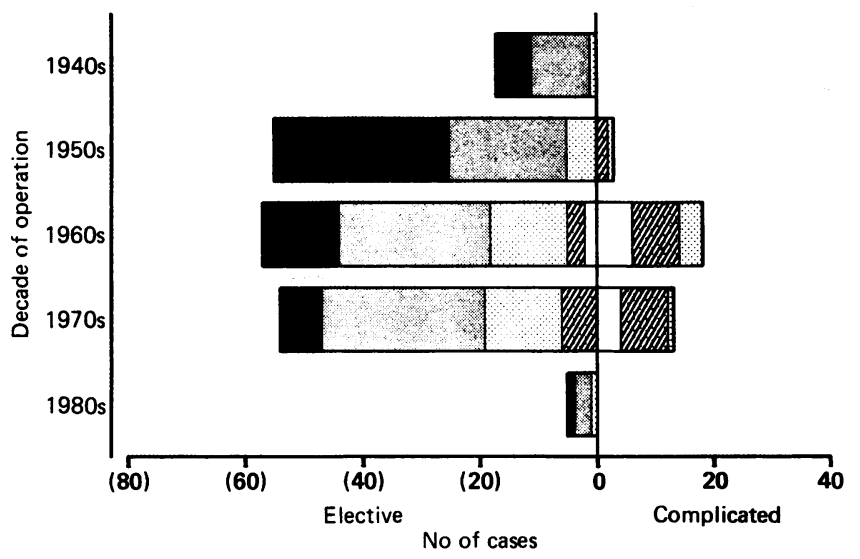

Figure 2 Age at operation by decade of operation.

Table 1 Ages at operation

\begin{tabular}{lll}
\hline Data & Elective & Complicated \\
\hline Total & 189 & 34 \\
Average age at operation & $12 \mathrm{yr}$ & 6 mnth \\
Range & $1 \mathrm{mnth}-48 \mathrm{yr}$ & 7 days-4 yr \\
Median age & $8 \mathrm{yr} 9 \mathrm{mnth}$ & $1.5 \mathrm{mnth}$ \\
Died < 1 day & $3(1.6 \%)$ & $15(40.5 \%)$ \\
Died <1 month & $5(2.6 \%)$ & $21(61.8 \%)$ \\
\hline
\end{tabular}

operation (189 patients) and those who required emergency or more immediate operation because of complicating factors including resistant heart failure, ductus arteriosus, or ventricular septal defect (34 patients). Patients were considered to have survived the operation and its immediate effects if they were alive 30 days from the date of operation (table 1).

Figure 1 shows the survival from operation by age at operation for the two categories. The mean age at operation was much less for the complicated cases; these operations were often emergencies performed on very young infants in severe heart failure, many of whom did not survive the operation. In contrast, over $97 \%$ of the patients who had elective operation were alive 30 days afterwards.

Nearly all $(91 \%)$ of the operations were performed between the early 1950s and the late 1970s-all of the "complicated" cases were operated on before 1980 . The patients who were operated on before the 1960 s tended to be older (fig 2). There was no obvious trend in operative survival over the decades (table 2); however, between 1968 and the end of the study period there were no early postoperative deaths among the 77 patients who had elective operations. Of the five deaths among 112 patients who had elective operations up to 1968, three were operated on before 1950 .

\section{LONG TERM RESULTS OF REPAIR}

Fifteen of the 197 patients known to have survived the operation were lost to follow up on discharge from hospital and were excluded from the analysis. Most of these were patients referred from abroad who returned to their homes after operation. Figure 3 shows all patients according to age at first operation. Twenty two of the 197 survivors died during the follow up. Five of these deaths were unrelated to coarctation or its repair. One patient died aged 5 from acute laryngotracheitis, three patients died from malignant neoplasms, and one drowned in a sailing accident; the last four all died after the age of 35 and had survived over 18 years since the repair of their coarctations.

The other 17 deaths could be attributed to coarctation, associated abnormalities, or the repair. All these patients had had end-to-end anastomoses. Table 3 summarises the age at operation, age at death, and underlying clinical cause of death in these patients. Five deaths were related to persistent coarctation; two of these patients died during further operations. Three other patients did not survive to the age of 20: one died aged 4 of septicaemia caused by acute bacterial endocarditis on a congenitally bicuspid valve (necropsy showed that the operation site was uninfected), one died aged 18 from congestive cardiac failure, and one at the age of 19 from an aneurysm related aorticoesophageal fistula. There were five further deaths from aortic aneurysms. According to the reports, none of these was related to the operation site: one occurred in the arch of the aorta; two in the ascending aorta; and the exact site was not specified in the remaining two patients. There were four deaths from congestive cardiac failure. Ventricular fibrillation caused death in a patient who had already had a short previous attack in the absence of any apparent cause. There were no deaths from cerebrovascular accidents.

Table 2 Early mortality by year operation

\begin{tabular}{|c|c|c|c|c|}
\hline \multirow[b]{2}{*}{ Year of operation } & \multicolumn{2}{|l|}{ Elective } & \multicolumn{2}{|c|}{ Complicated } \\
\hline & Number & Number (\%) died within 30 days & Number & Number $(\%)$ died within 30 days \\
\hline $\begin{array}{l}1946-49 \\
1950-59 \\
1960-69 \\
1970-79 \\
1980-81 \\
\text { Total }\end{array}$ & $\begin{array}{r}17 \\
55 \\
56 \\
55 \\
6 \\
189\end{array}$ & $\begin{array}{ll}3 & (17 \cdot 6) \\
1 & (1 \cdot 8) \\
1 & (1 \cdot 8) \\
0 & (0) \\
0 & (0) \\
5 & (2 \cdot 6)\end{array}$ & $\begin{array}{r}0 \\
3 \\
18 \\
13 \\
0 \\
34\end{array}$ & $\begin{array}{c}0(0) \\
1(33 \cdot 3) \\
13(72 \cdot 2) \\
7(53 \cdot 8) \\
0(0) \\
21(61 \cdot 7)\end{array}$ \\
\hline
\end{tabular}




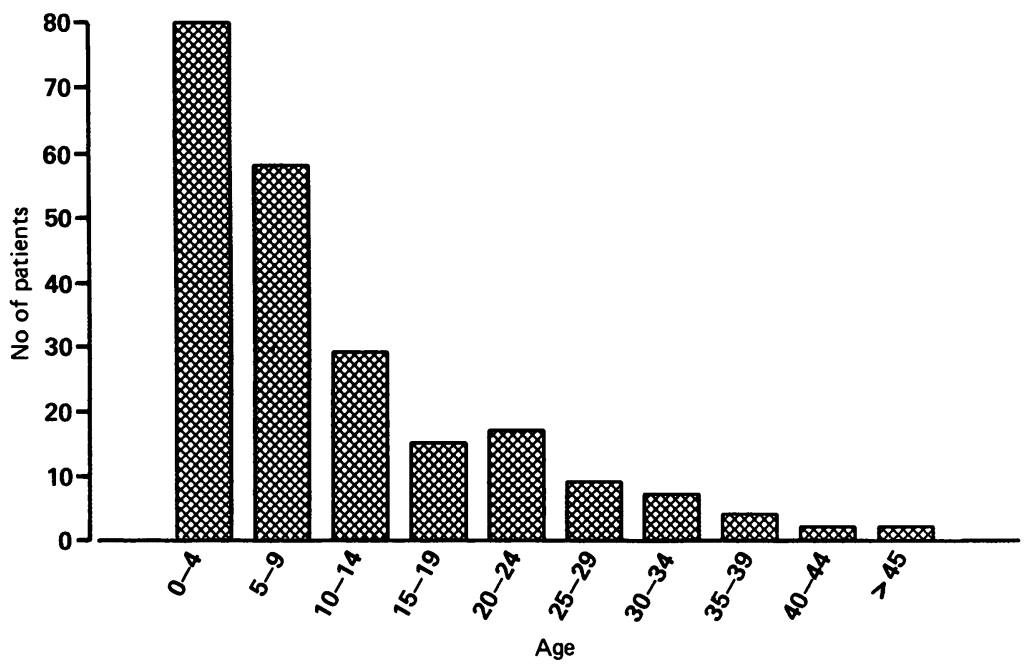

Figure 3 Cases by age at first operation.

The five patients who died from causes unrelated to their coarctation were considered as having left the study on their date of death. Figure 4 shows the survival and cumulative hazard functions: $3 \cdot 8 \%$ died in the 10 years after the repair of their coarctation, $4 \cdot 1 \%$ died between 10 and 20 years after the operation, and $9.2 \%$ died in the 10 years after that; thereafter mortality decreased. Only 27 people in the study were followed up for 30 years or more. It seems that even when general mortality was taken into account, the risk of dying from the effect of coarctation increased with the interval since operation. Only patients operated on before 1969 were followed up over 20 years, so the increase in mortality 20 years after operation might have been caused by problems with the early operative technique. But, because mortality by decade of operation showed no decline 10 and 15 years after operation, this seems unlikely.

\section{FACTORS AFFECTING LONG TERM SURVIVAL}

\section{Age at operation}

The patients were divided into three groups according to their age at operation-aged 4 years and under (56 cases), 5-14 years (76 cases), and $\geqslant 15$ years ( 50 cases). Figure 5 shows plots of the Kaplan-Meier survival curves for each group. There was no statistically significant difference at the 0.05 probability level (when an approximation to Cox's $F$ test was used) in long term survival between the groups, though a longer period of follow up might well indicate which age group fared the best. The best 20 year postoperative survival in our study was achieved by the $0-4$

Table 3 Information on 17 deaths related to cardiovascular disease

\begin{tabular}{rlrl}
\hline $\begin{array}{l}\text { Age at } \\
\text { operation } \\
(y r)\end{array}$ & $\begin{array}{l}\text { Age at } \\
\text { death } \\
(y r)\end{array}$ & Causes of death \\
\hline 1 & $6 \mathrm{wk}$ & 5 & Died during operation to correct recoarctation of aorta \\
2 & $3 \mathrm{mth}$ & 11 & Died during operation to correct recoarctation of aorta \\
3 & $4 \mathrm{mth}$ & 5 & Septicaemia, acute bacterial endocarditis \\
4 & 1 & 22 & Recurrent coarctation of aorta \\
5 & 5 & 19 & Aortic-oesophageal fistula (presumed aneurysm-details unavailable) \\
6 & 5 & 30 & Congestive cardiac failure \\
7 & 7 & 20 & Ventricular fibrillation (previous episode of VF-no other abnormalities apparent before fatal recurrence) \\
8 & 10 & 33 & Ruptured aortic aneurysm, persistent coarctation \\
9 & 11 & 22 & Acute heart failure, aortic incompetence, persistent coarctation \\
10 & 11 & 18 & Congestive cardiac failure \\
11 & 18 & 24 & Ruptured aortic aneurysm \\
12 & 25 & 57 & Aortic aneurysm, gross aortic incompetence \\
13 & 29 & 36 & Congestive cardiac failure, aortic incompetence \\
14 & 30 & 41 & Aortic aneurysm \\
15 & 30 & 40 & Ruptured aortic aneurysm \\
16 & 31 & 53 & Congestive cardiac failure, aortic stenosis, bacterial endocarditis \\
17 & 48 & 69 & Congestive cardiac failure \\
\hline
\end{tabular}

All except patient 2 had end-to-end anastomosis. The coarctation site was considered satisfactory or not mentioned in the necropsy report, unless otherwise stated.

Figure 4 (A) Long term survival in all cases, excluding perioperative deaths and $(B)$ cumulative hazard in all cases, excluding perioperative deaths.
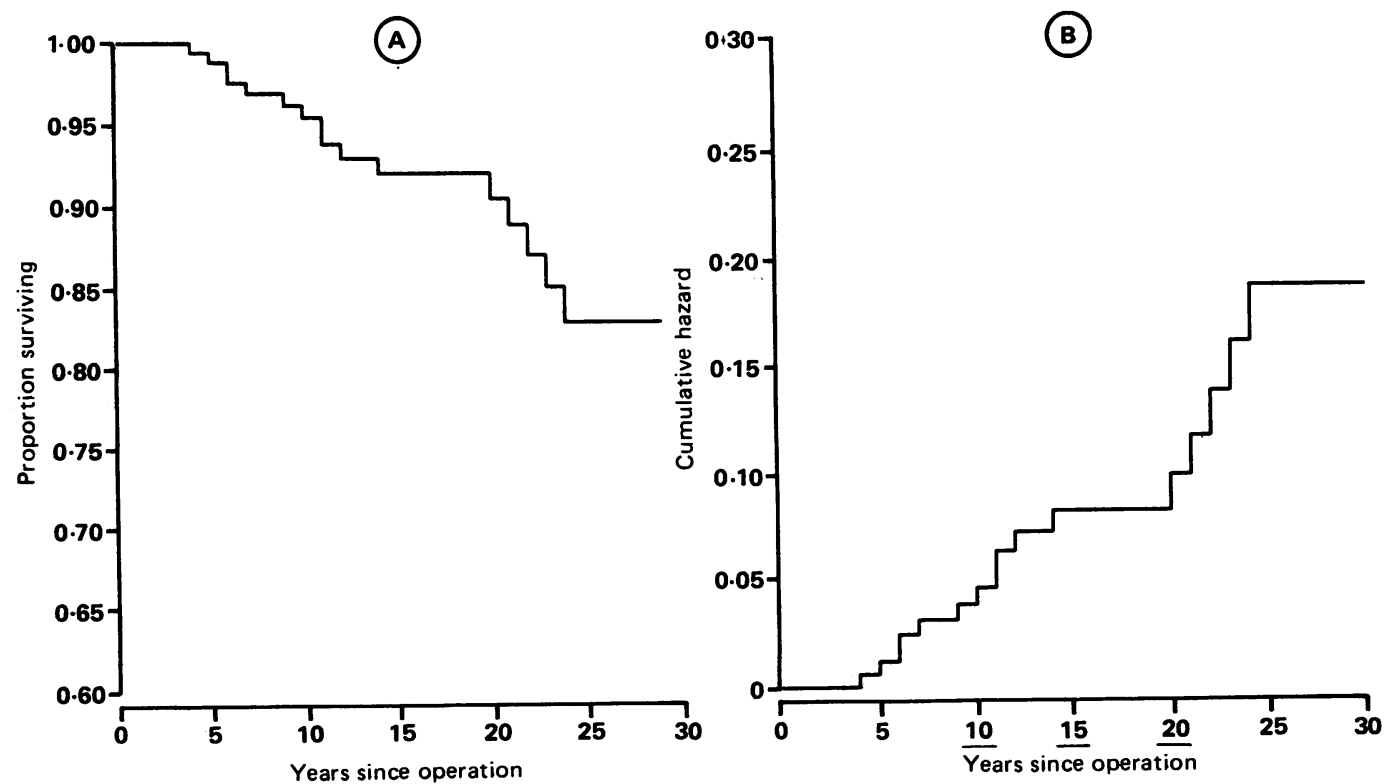
age group. Thirty year survival was similar for all three age groups; because of the small number of patients (27) who have been followed up for 30 years this finding is not very reliable.

Figure 5 Long term survival by age at operation, excluding perioperative deaths.

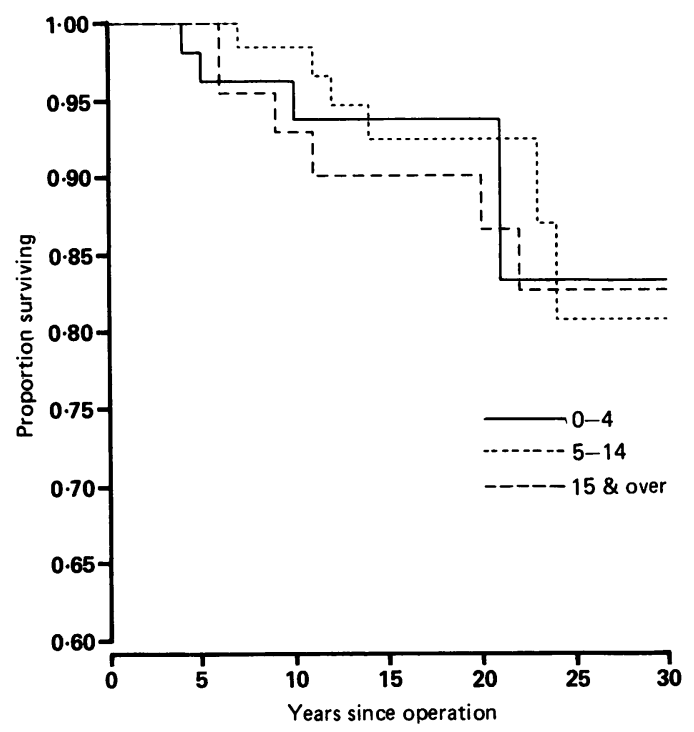

Figure 6 Long term survival according to blood pressure at operation and excluding perioperative deaths.
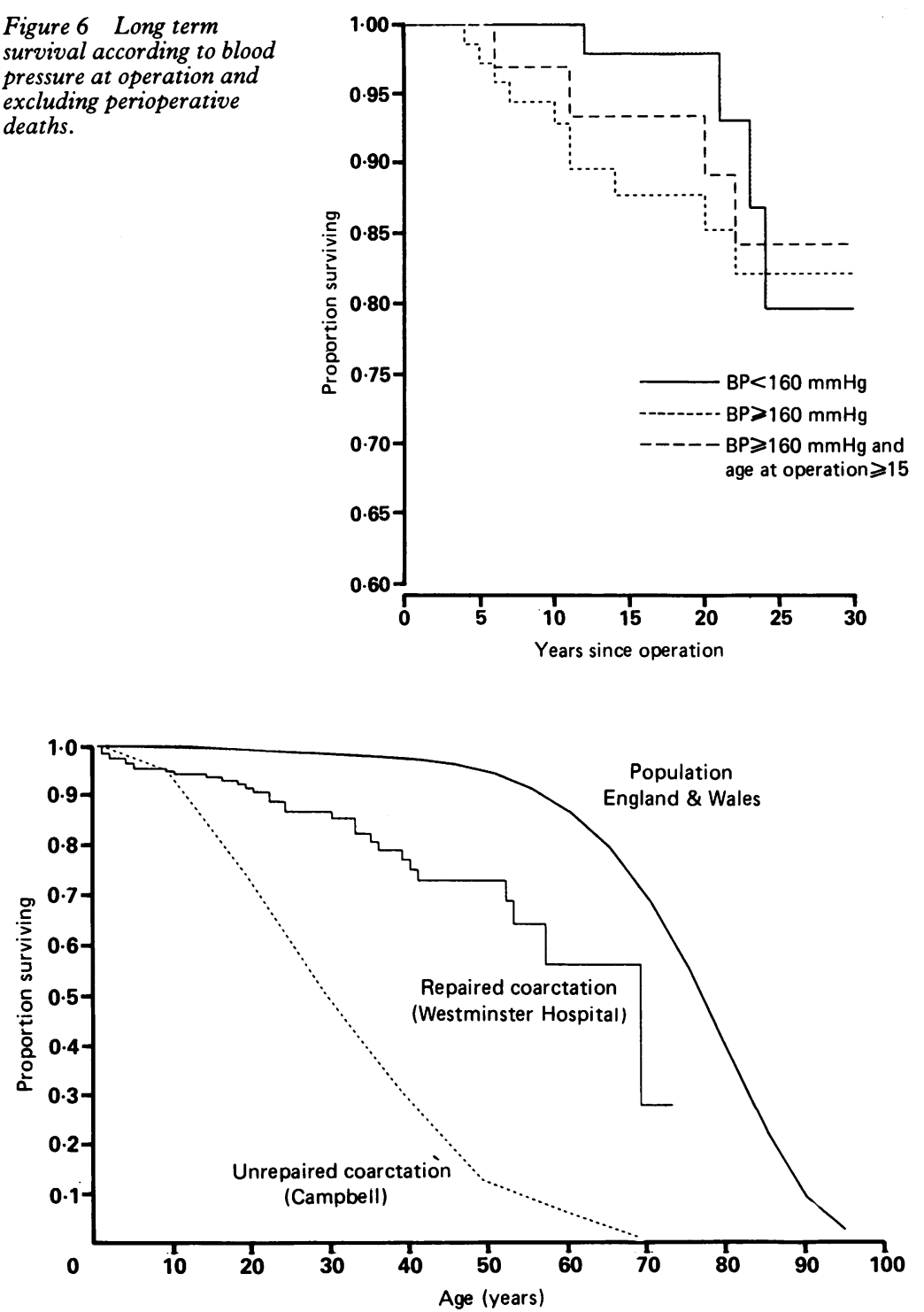

Figure 7 Comparative survival, excluding deaths in first year of life.

\section{Hypertension}

Figure 6 shows survival according to blood pressure at operation. Four of the 76 patients who had a systolic blood pressure of $<160 \mathrm{~mm} \mathrm{Hg}$ before the operation died in the follow up period compared with 10 of the 80 patients with a systolic blood pressure of $\geqslant 160 \mathrm{~mm} \mathrm{Hg}$; however, this was not statistically significant at the 0.05 probability level. Figure 6 also shows the survival of patients who had a systolic blood pressure of $\geqslant 160 \mathrm{~mm} \mathrm{Hg}$ and were aged $\geqslant 15$ when they were operated on. Though they had had prolonged preoperative hypertension, their late mortality was no higher than in other groups, and their 30 year survival was better than those with a preoperative blood pressure of $<160 \mathrm{~mm} \mathrm{Hg}$. For 26 patients we had no record of preoperative blood pressure.

OVERALL SURVIVAL

In 1970 Campbell estimated the mortality among patients who had coarctation of the aorta without surgical intervention. ${ }^{1}$ Figure 7 shows the proportion surviving plotted against age for his set of patients and the results from the present study and normal mortality in the general population of England and Wales. ${ }^{3}$ The results of our study are presented as an actuarial survival plot of the proportion surviving to reach each age, taking into account all deaths, whether perioperative or late unrelated to the coarctation. In all the plots, deaths under 1 year of age are excluded, because this is how Campbell calculated his figures. This plot showed that our patients survived longer than those with an unrepaired coarctation but not as long as the general population.

\section{Discussion}

Operative mortality for elective repair of coarctation of the aorta is $10 w^{4-6}-3 \%$ in our series of patients $(0 \%$ since 1968$)$. Without correction, the mean life expectancy of those with unoperated coarctation of the aorta is 35 years. Correction of the coarctation has been shown by this and many other studies ${ }^{5-10}$ to increase life expectancy.

Repair of aortic coarctation has been carried out since $1944 .^{2}$ As more patients enter their second, third, and fourth postoperative decades, problems associated with their coarctation and its repair are now becoming evident. Many studies have shown significant late mortality, ${ }^{45910}$ the rate being generally more than $10 \%$ when follow up exceeds 10 years. Some of our patients were followed up for 40 years and they included some of those who had the earliest operations for coarctation repair. The increase in mortality among these patients in the third decade after operation is worrying; Presbitero et al whose postoperative follow up ranged from 15 years to 30 years reported similar findings. ${ }^{7}$ So far, very few patients have been followed up into their fourth postoperative decade (27 in this series) and it is difficult to give a longer term prognosis, but it seems likely that problems caused by recoarcta- 
tion, vascular disease, and persistent hypertension will only increase with increasing age and time after operation.

Hypertension and vascular disease cause most of the morbidity and mortality associated with advancing age in patients with coarctation. Our results suggested an association between preoperative hypertension and an increased risk of later mortality. Others found that the younger the age at operation the greater the postoperative reduction in blood pressure ${ }^{11}$ with late hypertension being more common when the operation was delayed until after the age of $20.9^{9}$ Maron et al suggested that the duration of preoperative hypertension is an important factor, with prolonged preoperative hypertension and operation after age 25 increasing the risk of premature cardiovascular death. $^{6}$ In our series 23 patients, with a preoperative blood pressure $\geqslant 160 \mathrm{~mm} \mathrm{Hg}$ systolic were operated on after age of 20 and survived the operation; all of them are still alive and have survived an average of over 20 years. These findings endorse Liberthson $e t$ al's view that repair should not be denied on the basis of age or longstanding hypertension. ${ }^{12}$

The duration and severity of hypertension are also likely to be important factors in aneurysm formation remote from the repair site. Table 3 shows that in five of the six deaths related to aneurysms there had been exposure to hypertension and coarctation for more than 30 years in three, 25 years in one, and 18 years in two. Proximal distension, limited only by the degree and rate of development of collaterals, could be an equally damaging factor. Dissecting aneurysm of the ascending aorta caused late postoperative deaths in four patients and was detected in vivo in a further four of 343 survivors reported by Forfang et al..$^{13}$ In these patients surgical relief of coarctation occurred at age 9 (one) and at age 15-48 in the remainder. Aneurysm related to the repair patch is another hazard, discussed among others by Koller et $a l .{ }^{14}$ In the pre-surgical era, necropsy studies showed death from aneurysm rupture in $17 \cdot 1 \%$ of 304 patients with coarctation reported by Abbott ${ }^{15}$ and Reifenstein et al. ${ }^{16}$ In our series, we found an even higher proportion of deaths related to aneurysm $(27 \%)$, whereas so far there have been no deaths from cerebrovascular accidents, which accounted for $11.8 \%$ in the earlier necropsy series. ${ }^{15}{ }^{16}$ Relief of distension of the upper vascular segment and of hypertension after operation may be the reason; none the less aneurysm formation has persisted.

The desire to operate at an early age to reduce the risk of persistent hypertension and its associated problems must be balanced against the fact that residual and recurrent coarctation of the aorta are more common when the operation is undertaken in young patients, ${ }^{51011}$ though not necessarily with a worse outcome. ${ }^{10}$ Of the five late deaths in our series in which persistent coarctation was a contributory cause, three occurred in patients who had their initial operation at the age of 1 or less.

It was hoped that subclavian flap arterio- plasty $^{\mathrm{l} /}$ for the repair of coarctations would reduce recoarctation in infants. But this has not proved to be so. It seems that it is best to operate at the earliest age that gives the best results in the unit in which the operation is performed.

Doppler techniques, ${ }^{18} 19$ angiography, or magnetic resonance imaging ${ }^{20}$ can be used to show recoarctation of the aorta and other circulatory problems. Balloon dilatation may provide relief, and aneurysms can be monitored and operated on if indicated. These techniques mean that we can now do a more sensitive analysis than one based solely on mortality. It will then be possible to take prophylactic action to prevent further morbidity caused by recoarctation of the aorta, associated conditions, or problems associated with hypertension.

Additional work in progress shows that $80 \%$ of patients contacted claim to have experienced no symptoms or worsening in their quality of life after coarctation repair; yet many of the patients we re-examined $20+$ years after operation were hypertensive despite absence of recoarctation. These data will be submitted for publication in due course.

We thank the Garfield Weston Trust for providing the funds to start this project; the Department of Child Health, Westminster Children's Hospital, for help with administration; Miss Clare Jenkins and Dr Kevin Walsh (former Garfield Weston Research fellow) who helped with much of the early work; and Miss Joan Smith and Mrs Dorothy Taylor for backup for the study. We also thank Dr David Preston for his advice. Most of the patients included in this study were operated on by $\mathrm{Mr}$ Charles Drew and his team. Mr Drew was appointed to the staff of Westminster Hospital in 1951 and undertook much pioneering work on congenital heart disease. He died in May 1987.

1 Campbell M. Natural history of coarctation of the aorta. Br Heart J 1970;32:633-40.

2 Tawes R, Aberdeen E, Waterston D, Bonham Carter R. Coarctation of the aorta in infants and children. A review of 333 operative cases, including 179 infants. Circulation 1969;39,40 (suppl 1):173-84.

3 Office of Population Censuses and Surveys 1980-82. English Life tables No. 14. Series DS No. 7. England and Wales.

4 Simon A, Zlotto A. Coarctation of the aorta. Longitudinal assessment of operated patients. Circulation 1974;50: assessm

5 Schuster S, Gross R. Surgery for coarctation of the aorta. A review of 500 cases. J Thorac Cardiovasc Surg 1962;43: 54-70.

6 Maron J, O'Neal Humphries J, Rowe D, Mellitis E. Prognosis of surgically corrected coarctation of the aorta. A 20-year post-operative appraisal. Circulation 1973 ; 47:119-26.

7 Presbitero P, Demarie D, Villani M, et al. Long term results 15-30 years) of surgical repair of aortic coarctation. $B r$ Heart J 1987;57:462-7.

8 Crafoord C, Nylin G. Congenital coarctation of the aorta and its surgical treatment. J Thorac Surg 1945;14:347-61.

9 Clarkson P, Nicholson M, Barrat-Boyes B, Neutze J, Whitlock R. Results after repair of coarctation of the aorta beyond infancy: a 10 to 28 year follow-up with particular reference to late systemic hypertension. $\mathrm{Am} \mathrm{J} \mathrm{Cardiol}$ reference to late
$1983 ; 51: 1481-8$.

10 Cohen M, Foster V, Steele P M, Driscoll D, McGoon DC. Coarctation of the aorta. Long term follow-up and prediction of outcome

11 Nanton M, Olley P. Residual hypertension after coarctectomy in children. Am J Cardiol 1976;37:769-72.

12 Liberthson R, Pennington D, Jacobs M, Daggett W. Coarctation of the aorta: review of 234 patients and clarification of management problems. Am J Cardiol 1979;43:835-40.

13 Forfang K, Rostad H, Sörland S, Levorstad K. Late sudden death after surgical correction of coarctation of the aorta. Importance of aneurysm of the ascending aorta. Acta Med Scand 1979;206:375-9.

14 Koller M, Rothlin M, Senning A. Coarctation of the aorta Review of 362 operated patients. Long term follow up and assessment of prognostic variables. Eur Heart $J 1987$ 8:670-9.

15 Abbott ME. Coarctation of the aorta of the adult-type. II and III. Am Heart J 1928;3:392, 574

16 Reifenstein GH, Levin SA, Gross RE. Coarctation of the aorta; review of 104 autopsied cases of the "adult-type" 2 
years of age or older. Am Heart J 1947;33:146-68.

7 Penkoske $\mathrm{P}$, Williams W, Olley $\mathrm{P}$, et al. Subclavian arterioplasty. Repair of coarctation of the aorta in the first year of plasty. Repair of coarctation of the aorta in the firs

18 Gibbs JL. Ultrasound and coarctation of the aorta. Br Heart $J$ 1990;64:109-10.

19 Carvalho JS, Redington AN, Shinebourne EA, Rigby ML, Gibson D. Continuous wave Doppler echocardiography and coarctation of the aorta: gradients and fow patterns in the assessment of severity. Br Heart J 1990;64:133-7.

20 Rees S, Somerville J, Ward C, et al. Coarctation of the aorta MR imaging in late post-operative assessment. Radiology 1989;173:499-502.

\section{Addendum}

A further investigation into present state is underway. So far information is limited, but $68(80 \%)$ of the 85 survivors who were contacted because they had survived for 20 years or more consider themselves to be free of symptoms. Of the remaining 17 patients, 11 said they experienced some shortness of breath on exercise, such as running upstairs, five on more restricted exercise when walking upstairs, and only one when walking on the level.

So far, 22 patients have been reinvestigated 20-38 years after operation (mean 29) presently aged 21-51 years (mean 45 ) with age at operation being 1 month -45 years (mean 2 years). Blood systolic pressure readings $(\mathrm{mm} \mathrm{Hg}$ ) were as follows: $>160$ in two; $>150$ in four; $>140$ in three. Diastolic pressures were $>90 \mathrm{~mm} \mathrm{Hg}$ in eight.

Doppler assessment of the coarctation site showed velocities indicative of a gradient of between 0 and $30 \mathrm{~mm} \mathrm{Hg}$ (mean $8.75 \mathrm{~mm} \mathrm{Hg}$ ). One patient had had a further operation for recoarctation, and two had had aortic valve replacement. So far no patients have had important aortic valve gradients.

Further follow up work is in progress, but it seems that recoarctation is not primarily responsible for most of the late hypertension. 